\title{
A Grim Assessment of Sectoral Quality Assurance in the Era of Covid-19 in Sierra Leone
}

\author{
${ }^{1}$ Kabia Allieu B., ${ }^{2}$ Momoh, Edwin J. J., ${ }^{3}$ Oscar Oladipo H. \\ ${ }^{1}$ Dean, Faculty of Social and Management Sciences \& Senior Lecturer, Ernest Bai Koroma University of Science and Technology, \\ Sierra Leone \\ ${ }^{2}$ Vice Chancellor and Principal, Ernest Bai Koroma University of Science and Technology, Sierra Leone \\ ${ }^{3}$ Registrar, Ernest Bai Koroma University of Science and Technology, Sierra Leone
}

\begin{abstract}
Sierra Leone is a resilient country that has gone through political transitions and negative economic evolutions as a result of geometric shocks not limited to; the 11 year rebel war, the Ebola pandemic in 2013, and the recent past mud slide and flooding in the city of Freetown and other parts of the country; cholera outbreak and the closure of the mining companies and other businesses in the private sector that have been the major contributor for job creation and worsened the situation to the already vulnerable socio-economic status in the Country. A grim assessment of sectoral quality assurance was adopted purposely to give a clear understanding of the status of sectors in the Sierra Leone' economy as a result of the negative impact of the Covid-19 scourge that ravage the all regions in the country. The study reveals that, it was during the first quarter in $\mathbf{2 0 2 0}$ when Sierra Leone recorded its first Covid-19 pandemic case as the most recent in a series of natural and artificial disasters Sierra Leone has faced taking cognizance the 11 years civil war that spanned from 1991 to 2002, cholera in 2012, Ebola in 2014, flooding and a mudslide in 2017. Since the inception of the virus to June, 2021, 5,887 confirmed cases and 109 death cases were recorded in the country. The emergence of the Covid-19 on the economy in Sierra Leone has incubated a systemic/country risk effect creating quality Assurance challenges in economic sectors with huge tendency to reverse gains especially in businesses - both in the private and public sector. Worthy to note also from the study was that despite the negative ramification of Covid19 to all economic sectors has created an unfriendly environment in the economic sectors with quality assurance challenges, it gives rise to digitization in some facets of life especially the educational and commerce sector adopted the Learning Method System (LMS)- zoom Cloud e-learning platform and Podcasting that stimulate unlocking the potentials of businesses, academic staff, administrative staff and students.
\end{abstract}

Keywords: Sierra Leone, Quality Assurance, Sectoral, Covid19, Assessment.

\section{Introduction}

Sierra Leone is a relatively small country in West Africa within the Mano River Union block with approximately 7.2 million people. The country recorded its first Covid-19 pandemic case at the end of the first quarter in 2020. Covid-19 virus is the most recent in a series of natural and artificial disasters Sierra Leone has faced in recent years; the 11 years civil war that spanned from 1991 to 2002, cholera in 2012, Ebola in 2014, flooding and a mudslide in 2017. The emergence of the Covid-19 in the economic sectors in Sierra Leone has tendency to reverse gains and positive growth which subject the entire country into a systemic risk creating quality Assurance challenges especially in the educational, health and agricultural sector.

As at the 9th July, 2021, the statistics of the World Health Organization (WHO), ECDC and CDC for the Covid-19 outbreak in Sierra Leone and the globe recorded a total amount of 5,887 confirmed cases and 109 death cases; and 185,078882 confirmed cases and 4,001,791 deaths respectively.

Over the years, before the inception of the Covid-19 pandemic, Sierra Leone's economy had been categorized as an import-driven with export drivers dormant and one of the vulnerable emerging markets in Sub-Saharan Africa. Sierra Leone is a low income and Highly Indebted Poor Country (HIPC) that has gone through political transitions and rigorous negative economic evolutions as a result of geometric shocks. These shocks were: the 11 year rebel war that ended in 2002; the Ebola pandemic that erupted in late 2013; the recent past mud slide and flooding in the city of Freetown and other parts of the country; cholera outbreak and the closure of the mining companies who have been the major contributor for job creation worsened the already high rate of unemployment in the country. The Covid-19 outbreak in Sierra Leone in particular and the globe at large deteriorated the situation and exposed the country to more risks (health and non-health hazards). This Article is design to purposely have a grim impact assessment of Covid-19 on various sectors (economy, 
health, agriculture, education, investment and trade) in Sierra Leone. The study also highlighted Government responses and other Institutions approach in combating the Covid-19 plague.

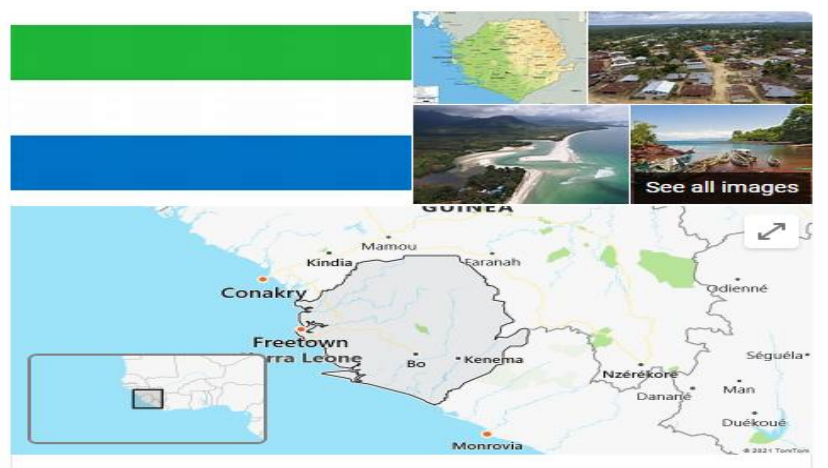

Sierra Leone

\section{Statistical estimates for Daily Confirmed New Cases of Covid-19 in Sierra Leone}

The World Health Organization (WHO), ECDC and CDC statistics estimate for Covid-19 outbreak in Sierra Leone from mid-February, 2021 to the third week in June recorded a total of 5,887 confirmed cases and 109 death cases.

\section{Confirmed cases}

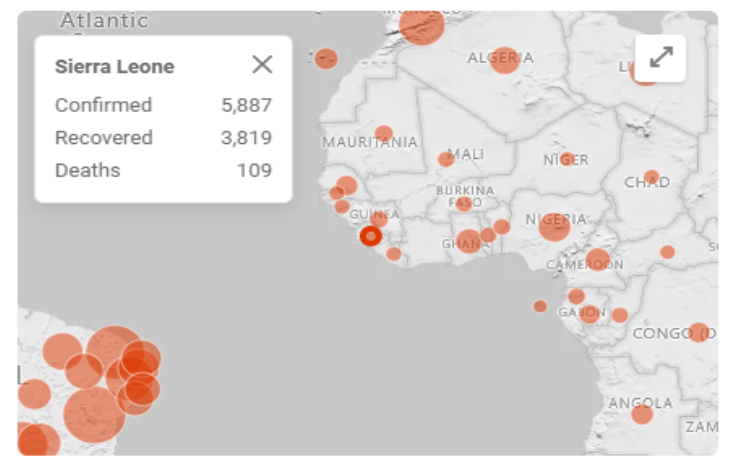

Data from: CDC - WHO - ECDC - Wikipedia - The New York Times - See full list - Increase in cases represents change over the last 24 hours

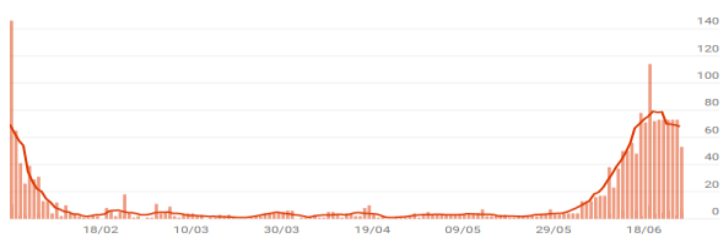

Cumulative cases

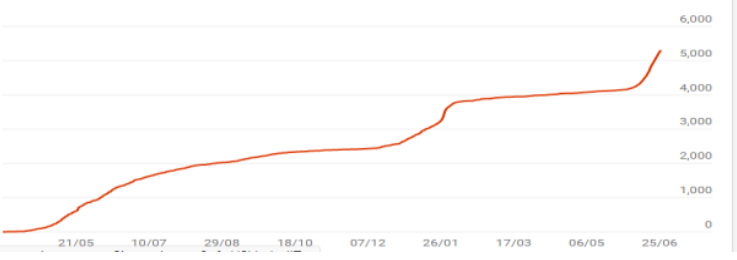

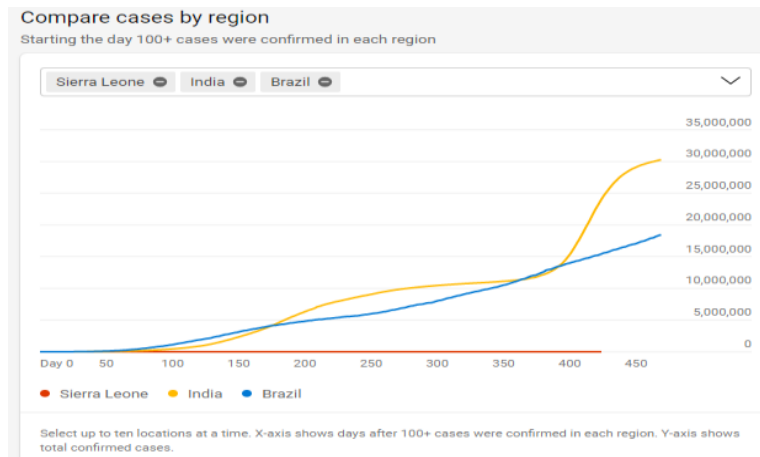

According to WHO statistics, At Global level, from midFebruary to the third week in June, 2021, the cases of Covid19 recorded 185,078882 confirmed cases and 4,001,791 deaths.

Daily New Vaccination

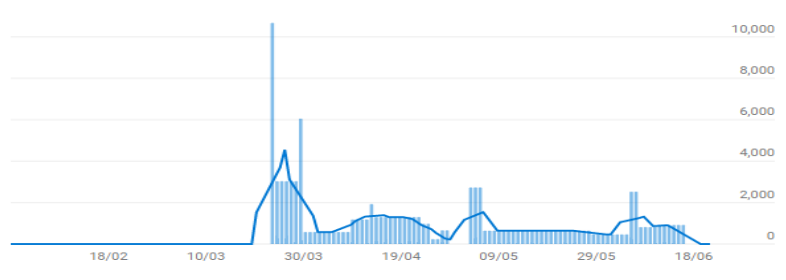

Cumulative vaccinations

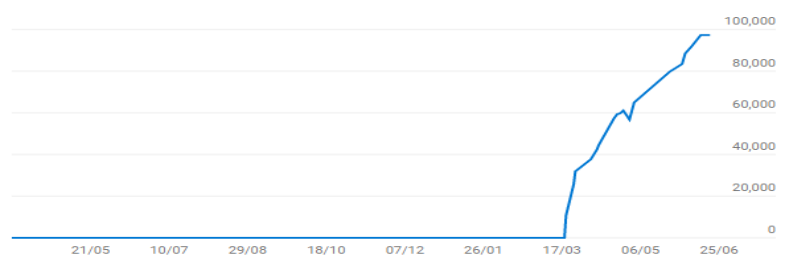

Cumulative New death

Cumulative deaths

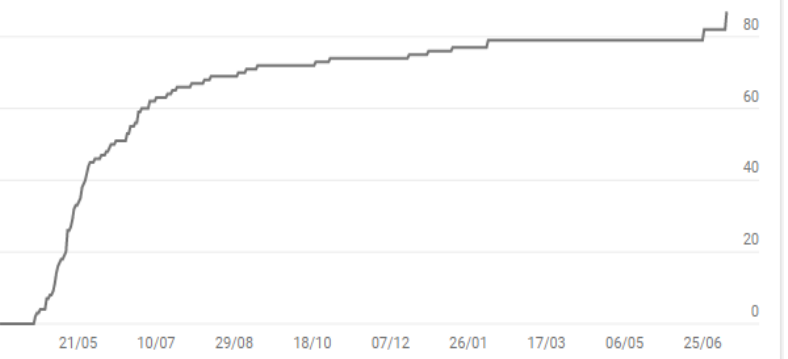

Source: WHO Statistics, 2021

\section{Sectoral Impact of Covid-19 in Sierra Leone}

The Covid-19 has a negative ramification to all sectors in Sierra Leone and created an unfriendly situation that has to do with quality assurance challenges within economic sectors especially the educational, agricultural and health sector to name but a few. 


\section{Economy}

The economic impact of Covid-19 in Sierra Leone cannot be underestimated and this has created harmful ramifications with breaks on economic drivers that stifle economic growth with a considerable systemic and country risk effect. This insinuated a battered economy to the already sluggish one before the scourge with huge leakages and less injections incubating an indication of economic recession. This resulted in a geometric decline in; gross domestic product, consolidated revenue fund, trade, investment and productivity. At the same time government expenditure, inflation and unemployment are on a sharp acute increase, which impedes human livelihood, poor standard of living, high cost of living, a rapid accelerated decline in economic empowerment and a multiplier increase in the public budget deficit .

The magnitude of the Covid-19 economic impact varies from one country to another. Currently, the presence of the virus in Sierra Leone just like other countries in SubSaharan Africa has created a proliferation stage for the economy to grabble with a mixture of several indicators such as; the lockdowns, social distancing, closing of borders, closure of private businesses and enterprises, hunger and fear of the disease and stigmatization which have impeded the economic activities of households and business entities. In Sierra Leone, few businesses in the private sector that were able to open have taken advantage of the scarcity of commodities by raising prices which has made the situation very unfavourable with an expensive and very high cost of living. The inability of individuals and business entities to carry out their normal business activities has led to a decrease in household incomes and business operating incomes respectively. The tremendous impact of the Covid-19 on food security has also negatively affected people's food consumption patterns. Many people have no alternative but to change their consumption habits and eat less, in contrast to before the Covid-19. For instance, people have shifted from the normal staple food, rice to 'gari' and cassava etc. because the latter are less expensive.

\section{Education}

The Covid-19 has had a significant impact on the educational sector which resulted in the shutdown of schools, colleges and universities across the country given rise to digitization adopting the e-learning method system in meeting the demands of the fourth industrial revolution which was very thought-provoking and educative. The zoom Cloud e-learning platform and Podcasting goes a very long way in unlocking the teaching and learning potentials of lecturers/teachers and students respectively. As a result, education has changed dramatically, with the distinctive rise of e-learning, whereby teaching is undertaken remotely and on digital platforms. Research suggests that online learning has been shown to increase retention of information, and take less time, meaning the changes corona virus have caused might be here to stay.

These institutions are fraught with difficulties and challenges of limited resources for the educational sector to adopt the Elearning model as well as brain drain and most of the schools infrastructures are going to be demolished to mitigate the risk of future pandemic ramification. In the education sector, lessons learned from past disasters, especially the Ebola epidemic, have been applied quickly in response to Covid-19.

After the government closed the schools and shut down the country, administrative and management staff within the Educational sector were challenged to think critically to identify best practices to get our students learning despite the Covid-19 situation pandemic given rise to digitization adopting the learning Method System(LMS) in the sector. The LMS model constitutes the zoom Cloud e-learning platform and Podcasting which goes a very long way in unlocking the teaching and learning potentials of lecturers/teachers and students respectively. Addendum to that, some of the lessons learned during the Ebola pandemic in Sierra Leone were identified and was used applied to ensure learning during the current Covid-19 plague. Such as:

1. Ensured that all Covid-19 safety measures (wearing a face mask, hand-washing, social distancing and stopping bodily contact) are practiced. Safety measures were also required wearing a face mask is new with Covid-19.

2. Radio teaching programs for all levels were designed and delivered across multiple radio stations alternatively to the e-learning model to reach all students within the country since there is limited access to internet in the country so online courses would not be viable. Teachers and head of schools were provided with psychosocial support and girl's safety training. Development partners were tasked with numerous community engagement activities to support and facilitate the learning process. Programs were put int place to support family engagement in student learning and gender based community activities were created to protect girls from harm/abuse. We hope these initiatives will minimize the damage of Covid-19 on our students.

3. Before the Covid-19 crisis struck, getting students back up to speed after the Ebola epidemic had been one of the government's objectives. An assessment of student performance completed in 2018 showed that the country was five years behind. The recently elected government made education a top priority and the budget allocation for the sector was significantly increased. A new 
curriculum called the Lesson Plan Manual was adopted to replace the Accelerated Learning Manual.

\section{Health}

The health system in Sierra Leone was already weak before the Covid-19 outbreak, and has become overwhelmed by the crisis. According to WHO, there are six components of a health system: (1) human resources; (2) governance and leadership; (3) financing; (4) commodities and supply chain networkers; (5) service delivery; and (6) information. The affected countries face severe deficiencies in each of these areas and the outbreak is exacerbating these challenges. This section describes how constraints in each component of the affected countries' health systems enable the virus to continue to spread.

1. In Sierra Leone, though the Covid-19 response is scaled up cases and deaths continue to occur, Riots are breaking out. Isolation centers are overwhelmed. Health workers on the front lines are becoming infected and are dying in shocking numbers. Others have fled in fear, leaving people without care and as result the human capital of the health sector has been seriously devastated and needs to be enhanced with a structured health system for a sustainable health sector in Sierra Leone

2. Governance Financing, Human Resources, Commodities Service Delivery, Information Description Policies, strategies, and plans that inform the course of action take to meet the health needs of the people, honestly lacks adequacy, efficiency, effectiveness and timely management of medical implementation

3. Insufficient financial resources to fund local responses and pay health personnel contribute to human resource and commodity shortages.

4. Shortages of not only health personnel, but also support staff like grave diggers and statisticians limit the ability to detect, prevent, and treat Covid-19 cases.

5. Insufficient supply of protective equipment threatens the safety of healthcare workers (including community volunteers) and is associated with hospital- and clinic based infections. Many health facilities in Sierra Leone remain closed due to staff shortages and other factors.

6. Limited capacity to conduct contact tracing and diagnosis calls into question the actual Covid-19 cases and impedes efforts to detect, treat, and control the virus.

In Sierra Leone, though the Covid-19 response is scaled up cases and deaths continue to occur, Riots are breaking out. Isolation centers are overwhelmed. Health workers on the front lines are becoming infected and are dying in shocking numbers. Others have fled in fear, leaving people without care and as result the human capital of the health sector has been seriously devastated and needs to be enhanced with a structured health system for a sustainable health sector in Sierra Leone.

\section{Agriculture}

Covid-19 outbreaks reverse the gains in agriculture in terms of output productivity and efficiency in farming activities. This has made food security to be a challenge in the country thereby not be able to provide for subsistence living. Most farmers were having Covid-19 health problems. Farmers need access to finances, training, machinery and good farming infrastructure to rebuild and sustain their farming activities for sustainable Agricultural productivity. FAO and IFAD need to scale up their previous support before the outbreak and other International plays also need to come on board.

\section{Exchange Rate \& International Trade}

The exchange rate has been unfavorable for Sierra Leone as a result of the plague due to the drastic fall of the Leone currency leads to a rise in the prices of goods and services. About Le10,000: \$1 as at August, 2021. Macro of goods in the economy are imported and that will lead to a net-trade deficit, so there is need for international player to boost international trade activities especially for importation of goods by creating a provision of deferred payment for 1 or 2 yrs for importers with a letter of credit from the customers bank in Sierra Leone through the Central Bank to the Central Bank of IPPs say China on behalf of a customer in a foreign commercial bank who is an exporter. This will lessen the high demand of forex in the country and will facilitate international trade as importers will be able to grow steadily with strength as a Covid-19 recovery plan. China is doing such transaction with importers from Tanzania, Kenya, and South Africa.

\section{Investment Opportunities}

Though the ebola crises has deterred investors in Sierra Leone that has also contributed to the fall in the GDP, Sierra Leone has long term investment opportunities, especially in the mineral and agri-business sector, so investing in development and major infrastructure will help speed up recovery by creating jobs and make the region more resilient in the long term, helping end dependency on Aid and better prepared for humanitarian crises.

\section{Macroeconomic policy Constraint}

The Fiscal, Monetary and Exchange rate policy have been have been hampered, Government is spending more whilst revenue mobilization drastically declined, financial system has been defective which is making the central bank not effectively and efficiently perform its traditional roles, foreign 
exchange rate is sky rocketing as a result of scarcity of foreign reserve whilst the demand for foreign currency increasing whilst supply declining.

\section{Financial System}

The performance of Financial Institutions decline drastically as a result of the menace; cut down on; time of operation, profit, customer base, savings, deposits, asset base, bank net worth, NPL increases, more bad loans, death of competent staff, brain drain etc. There is need as an ebola recovery plan for Financial Institutions to scale up there operations by mobilizing more savings to be able to give out more loans to investors; the Central Bank most Also present a proposal to the IMF \& World Bank to cut down banks statutory requirement cash and liquidity ratio to increase and enhance commercial banks propensity to give more loans to investors and investors will in turn create more jobs which will ultimately grow our economy with a safe and sound financial system. The Central Bank can only reduce the cash and liquidity ratio base on the endorsement of the IMF and World who are IPPS.

\section{Recommendations for policy Implication}

This outbreak has caused a negative impact in West Africa in general and Sierra Leone in particular. If this scourge is not eradicated totally, it will incubate tendency of economic losses and recession, social chaos and the masses will have political distrust to does in governance in the country.

The recent outbreak in West Africa of the highly infectious and often fatal Covid-19 virus highlights the need for global cooperation in health. The latest example of governments' inability to control the spread of infectious diseases when they act in isolation: global rules negotiated among governments are crucial to protecting the health of citizens.

The international community has also taken steps to supplement the actions of the three governments. The Economic Community of West Africa (ECOWAS) created a 'solidarity fund' to contain and manage the outbreak, and the World Health Organisation convened an emergency meeting of regional health ministers in Accra to strengthen surveillance operations and facilitate cross-border consultations.

The detail recommendation below should be taken by Sierra Leone to combat the Covid- 19 pandemic and strengthening the health sector;

(1) The current response needs to be heightened up. Opening sub-regional command centers, deploying personnel from governmental and nongovernmental sources, and providing financial resources are all important-but they need to be done in greater number and with greater urgency. The initial efforts are not necessarily failures; they are just too small and slow in response to the overwhelming nature of this unprecedented outbreak. There's need to foster agreement cooperation amongst neighboring countries to increase crossborder cooperation, engage local communities better, and foster collaborations with international partners. This may provide a solid foundation for ratcheting up a more aggressive response to the outbreak

(2) Efforts to provide health care services and outreach to affected communities need to take concerted efforts to integrate local, cultural contexts and health care measures into Ebola control. Rather than dismissing rumors as evidence of a lack of information, successful health interventions frequently try to tailor their messages in such a way that incorporate the rumors and the shared understandings about health and wellness that they embody. In other words, the problem is less one of ignorance and more one of trying to send a message that fails to resonate. By a similar token, measures that criminalize or stigmatize Ebola patients or those potentially infected with the disease are unlikely to encourage compliance. A more promising strategy is disseminating information in the form of song or comedy that will instructs listeners about the proper steps to take to avoid infection. Using music both gets around issues of illiteracy and reaches audiences who might overlook official government pronouncements.

(3) There is significant need to have a serious long-term effort plan framework to improve the health care systems, disease surveillance capabilities, and laboratory resources in Africa in general and all three MRU states hit with the virus in particular. Part of the reason for the delay between the first rumored cases of Covid-19 in March, 2021 and the official announcement in early April was because laboratory facilities that were available lack necessary tools to conduct the necessary tests. Undertaking a long-term campaign to strengthen such systems would allow government to respond more quickly and have a greater chance of stopping any future outbreak. They would also help build strong ties between government and the rest of the international community to further the promotion of health.

(4) The international players should help Africa in general and Sierra Leone in particular to build better and sustainable economies that will finance building better structure and infrastructure of different sectors in the economy especially the health sector. It is no secret.

\section{Conclusion}

Sierra Leone is a resilient nation. It has worked hard to ensure the pandemic is put under control even though it's a 
ISSN (online): 2581-3048

country with lots of obstacles in almost every sector as a result of the triple shocks in the country's economy.

In view of the aforesaid grim assessment on the impact of Covid-19 in Sierra Leone, the Covid-19 policy responses should demand adequate consideration for the current unbearable and alarming situation. This will enable the Government of Sierra Leone to consolidate efforts with clear goals to reactivate and reinvigorate the already frozen economic drivers and engines to mitigate the huge national, regional, continental and global economic impacts in the country there by fuelling and giving life back to the economy. As an import-driven economy with export drivers dormant, Sierra Leone needs to be flexible in its border limitations to create an enabling environment of opening up to allow the inflow of goods from other countries to cushion the effect of the corona virus pandemic. In addition, proactive measures are also needed with sound, timely and adequate policies for urban and rural economic recovery through measures to boost finances and capacities of local authorities. The local governments as first responders in communities must be supported because they are better able to respond to local needs including in coordination with community-based structures, subsidies and short term bailouts and exemptions for small and medium enterprises to enhance productivity and reduce the high unemployment rate. The authorities could also offer; social protection and automated stabilizers while looking forward to the opportunities and potential of labour intensive public work programs to absorb the already high unemployment rate in the medium term.

\section{REFERENCES}

[1] Thamer A.N. Alenezi. "The impact of Covid-19 on construction project in Kuwait," International Journal of Engineering Research and General Science Volume 8, Issue4, July-August, 2020 ISSN 2091-2730.

[2] Dr. Aishath Shehenaz Adam. "The impact of Covid-19 on the construction sector of the Maldives," Phase 1: Initial Assessment, August 2020.

[3] Abebe Dimissew Gashahun. "Assessment on Impact of Covid-19 on Ethopian construction Industry."Volume 10 Issue No.7 ISSN 2321 @ 2020 IJESC.
[4] Emily Bohannon. "The effect of Covid-19 on the commercial construction Industry in California: A case study."(Unpublished).

[5] Tariq Al Amri, Manuel Marey-Perez. "Impact of Covid19 on Oman's construction Industry." Vo. 9, 661-670. July 2020. ISSN: 2668-7798 DOI: $10.47577 /$ tssjv9i1.1021.

[6] Dr.Khair, Al-DeenBsisu, "The impact of Covid-19 pandemic on Jordanian Civil Engineering and construction industry. "International Journal of Service Science, Management and Technology vol.13 Issue 2, March-April $2022 . \quad$ DOI: 10.4018/IJSSMET.20220301.oa1.

[7] Tariq Umar, "The impact of Covid-19 pandemic on Jordanian Civil Engineers and construction industry." International Journal of Engineering Research and Technology. ISSN 0974-3154 Vol. 13 Issue 2. MarchApril 2022. DOI: 10.4018/IJSSMET. 20220301.oa1.

[8] May Khalfan, Mona Ismail, "Engineering project and crises management: A descriptive study on the impact of Covid-19 on Engineering project in Bahrain" Second International Sustainability and Resilience Conference Technology and innovation in Building Designs 2020IEEE. DOI: 10.1109/IEEECONF51154.2020.9319948.

[9] Ahmad Ghandour, "The impact of Covid-19 on project delivery: A perspective from the construction sector in the united Arab Emirates, "Humanities and Social Sciences Reviews eISSN: 2395-6518. Vol 8. No 5. 2020. Pp 169-177. https://doi.org/10.18510/hssr.2020.8516.

[10] Ankit Kumar Tripathi, "Impact of Covid-19 on concrete construction \& innovative ways to make it sustainable \& economical." International Journal of Science and Research (IJSR) ISSN: 2319-7064 Volume 9 Issue 8. August 2020. DOI: 10.21275/SR20808224841.

[11] Dr. Yaser Gamil, Abdulsalam Alhagar. "The impact of pandemic crises on the survival of construction industry: A case study of Covid-19." Mediterranean Journal of Science Sciences, Vol. II No.4, July 2020. DOI: https://doi.org/10,36941/mjss-2020-0047.

\section{Citation of this Article:}

Kabia Allieu B., Momoh, Edwin J. J., Oscar Oladipo H., "A Grim Assessment of Sectoral Quality Assurance in the Era of Covid-19 in Sierra Leone" Published in International Research Journal of Innovations in Engineering and Technology IRJIET, Volume 5, Issue 11, pp 4-9, November 2021. Article DOI https://doi.org/10.47001/IRJIET/2021.511002 